Original Article

\title{
FORMULATION OF KETOCONAZOLE LOADED NANO DISPERSIVE GEL USING SWOLLEN MICELLES TECHNIQUE AND ITS IN VITRO CHARACTERIZATION
}

\author{
MOHAMMAD IRSHAD REZA*, DIVYA GOEL, RAHUL KUMAR GUPTA, MUSARRAT HUSSAIN WARSI
}

Department of Pharmacy, School of Medical and Allied Sciences, Galgotias University, Greater Noida 201307, Uttar Pradesh, India Email: irshadreza0786@gmail.com

Received: 30 Dec 2017 Revised and Accepted: 13 Feb 2018

\begin{abstract}
Objective: The objective of the present work was to formulate and characterize nano dispersive gel (NDG) for topical delivery of water-insoluble antifungal agent ketoconazole in order to enhance its solubility, penetration through the skin and antifungal activity.

Methods: Nano dispersion of the drug was first prepared by swollen micelles technique (SMT) using tween 80 and chloroform which is then incorporated into the gel using carbopol 934. Ten formulations of ketoconazole loaded NDG was prepared and characterized for different physicochemical parameters like homogeneity, $\mathrm{pH}$, spreadability, extrudability, practical yield, drug content, in vitro drug release, ex vivo permeation study, and biological parameter antifungal activity.

Results: The formulated topical preparation exhibit $\mathrm{pH}$ in the range of 6.5 to 7.4 , and unveiled excellent homogeneity, spreadability and extrudability. Out of 10 formulations, formulation F4 showed maximum drug content of $95.56 \pm 1.13 \%$ and practical yield of $97.23 \pm 0.51 \%$. The in vitro drug release studies were performed using $\mathrm{pH} 7.4$ phosphate buffer. Formulation F4 showed best in vitro drug release $96.52 \pm 0.52 \%$ at the end of $24 \mathrm{~h}$ of study. Ex vivo permeation study of formulation F4 carried out using franz diffusion cell, also manifested good permeation and flux of drug across the chicken skin. Antifungal activity test of formulation F4 was carried out by the cup plate method using Aspergillus niger strain against marketed ketoconazole unveiled higher antifungal activity than marketed one.
\end{abstract}

Conclusion: The study confirmed formulation F4 to be an optimized and promising formulation for the effective treatment of topical fungal infections with enhanced solubility and penetration through the skin.

Keywords: Fungal infection, Ketoconazole, Nano dispersive gel, Swollen micelles technique, Carbopol 934, Tween 80

(C) 2018 The Authors. Published by Innovare Academic Sciences Pvt Ltd. This is an open access article under the CC BY license (http://creativecommons.org/licenses/by/4.0/] DOI: http://dx.doi.org/10.22159/ijpps.2018v10i3.24552

\section{INTRODUCTION}

Infections are caused by fungus ranges from superficial conditions of the skin (e. g., athletes foot and ringworm) and nails (e. g., onychomycoses) to the deadly contagious disease [1]. Ringworm also called dermatophytosis usually manifest as a series of rapidly expanding irritating lesions which can occur in any area of the skin, chiefly attack stratum corneum of keratinized tissues and hair fibres resulting in autolysis of the fibre structure, breaking off the hair and alopecia [2].

Ketoconazole is widely used recent synthetic imidazole ringcontaining powerful antifungal agent active against most of the species of fungi and yeast. A topical preparation of ketoconazole is used for the treatment of infections caused by a wide variety of fungi like candida and tinea [3]. In biopharmaceutics classification system (BCS), ketoconazole is classified as a class-II drug, based on its absorption and dissolution property, since it has a high permeability but its solubility in aqueous media is insufficient for the whole dose to be dissolved in the gastrointestinal (GIT) fluids under normal condition [4]. It is very lipophilic, practically it is insoluble in mineral oil $(<0.01 \%)$, and in solvent with alkaline $\mathrm{pH}$ but it is freely soluble in most of the organic solvents including chloroform, noctanol, ethyl alcohol, methanol, dimethyl sulfoxide (DMSO) [5]. It is least stable at $\mathrm{pH} 1$ and most stable at $\mathrm{pH} 7$ [6]. The poor aqueous solubility of ketoconazole is the limitation for topical delivery [3].

Topical drug delivery systems are extensively used for the treatment of local skin disorders. Topical application of drugs has potential advantages of delivering the drug directly to the site of action for an extended period. It bypasses the first pass metabolism, avoids problems related to absorption, changes in $\mathrm{pH}$ and also avoids risk and inconvenience of intravenous (IV) therapy [7, 8]. However, stratum corneum the top layer of the epidermis is the major barrier of drug penetration through the skin. For transdermal delivery, ideally, the drug should have low molecular weight ( $\leq 500 \mathrm{Da})$, high lipophilicity and effective at low dosage. Considerable attention has been focused in the last few decades to develop novel drug delivery systems (NDDS), to lower stratum corneum barrier and increase permeability [9]. This approach mainly includes electrophoresis, iontophoresis, sonophoresis, chemical permeation enhancers, microneedles, tape stripping, nanoparticles, nanodispersion [13] and vesicular systems including liposomes, niososmes, ethosomes and transferosomes $[10,11]$. Developed liposomes and niosomes, having high permeability, controlled release and target specificity but liquid nature of topical liposomes and an aqueous suspension of niosomes may have problems associated with physical instability such as fusion, aggregation and leaking of the entrapped drug $[3,10$, 12]. Nanodispersion plays an efficient role in the topical delivery of poorly aqueous soluble or insoluble drug whereby decrease of molecule size to nanoscale measurements leads to a massive expansion in the surface area that enables the faster penetration of medication through the skin and upgrades the drug bioavailability. This is often because of the rise in solubility of the drug on the reduction of particle radius. Terribly microscopic particle size causes an oversized reduction in gravity force and therefore the brownian motion could also be sufficient for overcoming gravity. This implies that no deposition happens on storage [13].

Topical preparations like ointments, creams, lotions are extensively used as topical agents have numerous disadvantages. Generally, they are very sticky causing discomfort to the patient. Likewise, they also increase the contact time $[8,14]$. Unlike other topical preparations, the gel is non-sticky, does not cause discomfort to the patient. Drug release is faster in gel formulation compared with ointments and creams. It also has more spreading co-efficient than ointment and cream $[15,16]$. Hence in the present study attempt has been made to formulate and characterize NDG of ketoconazole. NDG is semisolid dosage form formed by the combination of nanodispersion and gel. 
The gelling agent is added in nanodispersion that gives NDG. NDG overcomes the limitation of poor aqueous solubility of ketoconazole with the advantages of gel.

\section{MATERIALS AND METHODS}

Ketoconazole was received as a gift sample from Vonstachem Ltd, Delhi. Carbopol 934, triethanolamine (TEA), tween 80, chloroform, disodium hydrogen phosphate and potassium dihydrogen phosphate were provided by Galgotias University, Greater Noida. Strains of Aspergillus niger were purchased from the Institute of Microbial Technology (IMTECH, Chandigarh, India). All other chemicals used were of analytical grade.

\section{Preparation of nanodispersion of ketoconazole}

Nanodispersion of ketoconazole was prepared by a special technique called the formation of SMT [13]. The drug was dissolved in sufficient volume of chloroform and then tween 80 were added continuously with stirring. After complete addition of tween 80 in the final mixture, further stirred for $2 \mathrm{~d}$ to provide controlled and complete evaporation of chloroform. This leads to the formation of a system with ultra-low interfacial tension as well as drug particle size in nanoscale. Finally, ample volume of phosphate buffer $(\mathrm{pH}$ 6.8) was added to give nanodispersion. Formation of viscous mixture ensures the complete removal of chloroform.

\section{Preparation of ketoconazole loaded nano dispersive gel}

Carbopol 934 in required quantity was added to the ketoconazole nanodispersion with constant stirring at $500 \mathrm{rpm}$ for $2 \mathrm{~h}$. Speed was reduced later to avoid air entrapment. Finally, TEA was added to neutralize the mixture and provide appropriate consistency [17]. Different formulations were developed by varying tween 80 and carbopol 934 concentrations (table 1).

Table 1: Composition of different formulations

\begin{tabular}{|c|c|c|c|c|c|c|c|c|c|c|}
\hline Ingredients & F1 & F2 & F3 & F4 & F5 & F6 & F7 & F8 & F9 & F10 \\
\hline Ketoconazole (\%) & 2 & 2 & 2 & 2 & 2 & 2 & 2 & 2 & 2 & 2 \\
\hline Tween $80(\%)$ & 1 & 1.5 & 2 & 2.5 & 3 & 3.5 & 4 & 4.5 & 5 & 5.5 \\
\hline TEA (ml) & 0.5 & 0.5 & 0.5 & 0.5 & 0.5 & 0.5 & 0.5 & 0.5 & 0.5 & 0.5 \\
\hline Carbopol $934(\%)$ & 0.25 & 0.5 & 0.75 & 1 & 1.25 & 1.5 & 1.75 & 2 & 2.25 & 2.5 \\
\hline
\end{tabular}

TEA: Triethanolamine

\section{Characterization}

Prepared formulations were characterized for different parameters including physical appearance and homogeneity, $\mathrm{pH}$ determination, spreadability, extrudability, percent practical yield, drug content, in vitro dissolution, ex-vivo permeation and antifungal activity.

\section{Physical appearance and homogeneity}

All the NDG formulations containing ketoconazole were visually inspected for clarity, homogeneity, colour, presence of particles and fibres [18]. Grades were allotted (+++excellent; ++good; +fair).

\section{Determination of $\mathrm{pH}$}

Digital elico $\mathrm{pH}$ meter was used to check the $\mathrm{pH}$ of NDG at room temperature. At first, the $\mathrm{pH}$ meter was calibrated utilizing standard buffers of $\mathrm{pH} 4$ and 9.2. Precisely $2.5 \mathrm{~g}$ of gel was weighed and dispersed in $25 \mathrm{ml}$ of distilled water and after that $\mathrm{pH}$ meter was plunged in the dispersion and the $\mathrm{pH}$ was measured. The $\mathrm{pH}$ measurement of each formulation was done in a triplicate manner and average values were calculated [19].

\section{Spreadability study}

For the determination of spreadability [7] of the prepared NDG formulations a wooden block was taken which is provided by a pulley at one end. Spreadability was determined on the basis of 'Slip' and 'Drag' properties of NDG. A ground glass slide was taken and fixed on this block. An excess of NDG (about 2 g) collected and applied on this ground slide. The NDG was then embedded between this slide and another glass slide having the dimension of the fixed ground slide. On the top of the two slides, a $1 \mathrm{~kg}$ weight is placed for 5 min to provide a uniform film of the NDG and to expel air. The top plate is then subjected to pull of $80 \mathrm{~g}$. The time required by the top slide to cover a distance of $7.5 \mathrm{~cm}$ was noted. Spreadability of each formulation was done in a triplicate manner and average values were calculated by using the formula given below.

$$
\mathrm{S}=\mathrm{M} \times \mathrm{L} \div \mathrm{T}
$$

Where,

\section{$\mathrm{S}=$ Spreadability}

$\mathrm{M}=$ Weight tied to upper slide.

$\mathrm{L}=$ Length of glass slides.

$\mathrm{T}=$ Time taken to separate the slides completely from each other.

\section{Extrudability}

Method of extrudability study [4] of NDG formulation was based upon the quantity in the percentage of gel extruded from the tube on the application of certain load. More the quantity extruded better was extrudability. The NDG was filled in a clean, aluminium collapsible $10 \mathrm{~g}$ tube with $5 \mathrm{~mm}$ opening nasal tip. This tube was subsequently placed in between two glass slides and was clamped. A constant load of $1 \mathrm{~kg}$ was placed on the slides and gels extruded was collected and weighed. Extrudability of the gel was then determined by weighing the amount of gel extruded through the tip when a load was put. The percentage of gel extruded was calculated and grades were allotted (+++excellent; ++good; +fair).

\section{Practical yield (PY)}

PY [4] helps in selection of an appropriate method of preparation. It was calculated to know about percent yield and efficiency of the preparation method. NDG was collected and weighed to determine the PY of each formulation in triplicate manner and average values were calculated from following and noted down.

$\mathrm{PY}=$ Practical mass $(\mathrm{NDG}) \div$ Theoretical mass (drug+carrier) $\times 100$

\section{Drug content}

To determine drug content [20], NDG equivalent to $5 \mathrm{mg}$ of model drug was taken and dissolved in $5 \mathrm{ml}$ of methanol. The solutions were filtered and were further diluted such that the absorbance falls within the range of the standard curve. The absorbances of solutions were determined at $215.80 \mathrm{~nm}$ by UV-visible spectrophotometer. The actual drug content of each formulation was estimated using the following formula in triplicate manner and average values were noted down.

$\%$ drug content = Actual drug content in weighed quantity of gel/ Theoretical amount of drug in gel $\times 100$

\section{In vitro dissolution studies}

In vitro release studies of various samples of NDG were carried out using biological egg membrane [16]. A fresh chicken egg was carefully broken and its outer membrane was removed with necessary precautions without tearing/damaging and soaked overnight in the dissolution medium [7]. The egg membrane with a surface area of 3.14 $\mathrm{cm} 2$ available for diffusion was mounted on a franz diffusion cell. A known amount of NDG was weighed and applied on the membrane mounted on franz diffusion cell from the donor side. The receptor compartment was filled with $15 \mathrm{ml}$ of phosphate buffer. The 
temperature was maintained at $37 \pm 0.5^{\circ} \mathrm{C}$. The receptor compartment was constantly stirred at $100 \mathrm{rpm}$. Samples from the receptor fluid $(0.5 \mathrm{ml})$ were withdrawn at various time intervals $(30 \mathrm{~min}, 1 \mathrm{~h}, 2 \mathrm{~h}, 4$ h, $6 \mathrm{~h}, 8 \mathrm{~h}, 12 \mathrm{~h}, 16 \mathrm{~h}$, and $24 \mathrm{~h}$.) and replaced immediately by the fresh buffer solution. The samples were then analysed to determine absorbance spectrophotometrically using UV-vis spectrophotometer (Shimadzu Corporation, Japan 1800) at $215.80 \mathrm{~nm}$. Cumulative percent drug release of the various formulation was calculated in triplicate manner and average values were noted down $[7,12]$.

\section{Ex vivo permeation study}

To perform ex vivo permeation study $[21,22]$ of formulation showing better release (formulation F4) and marketed formulation (phytoral), franz diffusion cell was chosen. The selected franz diffusion cell was having effective diffusion area of $3.14 \mathrm{~cm}^{2}$ and cell volume of $15 \mathrm{ml}$. Freshly slaughtered chicken skin [23] was taken from the local slaughter house and soaked in sodium bromide solution for $5 \mathrm{~h}$ and then washed with water in order to remove adhering fat tissue. The outer layer (epidermis) was washed thoroughly with water, dried at 25\% RH and stored in the freezer until further use. Skins were allowed to hydrate for $1 \mathrm{~h}$ before being mounted on the franz diffusion cell. A suitable size of chicken skin was cut and mounted in the franz diffusion cell in such a way that the dermis faces receiver compartment and stratum corneum faces donor compartment. A known amount of formulated gel was loaded in the donor compartment. The receptor compartment was filled with $15 \mathrm{ml}$ of phosphate buffer $\mathrm{pH}$ 7.4. The temperature was maintained at $37 \pm 0.5{ }^{\circ} \mathrm{C}$. Magnetic beads of suitable size was placed inside the receiver and then this assembly was placed on a magnetic stirrer and stirred for $24 \mathrm{~h}$. The samples ( $0.5 \mathrm{ml}$ aliquots) were withdrawn from the receptor cell at a regular time interval and were analysed spectrophotometrically (Shimadzu Corporation, Japan 1800) at wavelength $215.80 \mathrm{~nm}$. Same procedure was repeated for normal marketed ketoconazole gel (phytoral). The cumulative amount of drug permeate across the skin was determined as a function of time of both the samples in triplicate manner and average values were noted down. Permeability coefficient and flux were also calculated using the following standard formula [5].

Permeability coefficient (apparent permeability) Where,

Papp $=($ Va/Area $\times$ time $) \times([$ drug $]$ acceptor $/[$ drug $]$ donor $])$

$\mathrm{Va}=$ volume in acceptor compartment

Area $=$ surface area of the intestinal membrane

Time $=$ total transport time

Flux (J)

$$
\mathrm{J}=\mathrm{Papp} \times \mathrm{CD}
$$

where $\mathrm{CD}=$ concentration of donor solution.

\section{Antifungal activity}

"Cup plate method" $[9,22]$ was opted to determine the antifungal activity of optimized formulation F4, in comparison with normal marketed ketoconazole gel (phytoral). Fungal strain Aspergillus niger as the test microorganism was used. An inoculum of Aspergillus niger was spread over the sabouraud's dextrose agar media and allowed to solidify in the petri dish. After solidifying the agar plate, cups were made with sterile borer $(5 \mathrm{~mm})$. By using a sterile syringe, $0.5 \mathrm{ml}$ of NDG solution was filled in into one cup and marked with ' $\mathrm{S}$ ' similarly $0.5 \mathrm{ml}$ of marketed gel solution was filled in another cup and marked with ' $\mathrm{M}$ '. This plate then kept for incubation for $24 \mathrm{~h}$ at $37{ }^{\circ} \mathrm{C}$ temperature. After incubation, the zone of inhibition was calculated and compared.

\section{RESULTS AND DISCUSSION}

In the present research work ketoconazole NDG were prepared using tween 80 along with carbopol 934 in different proportions by the technique called formation of SMT. The prepared ketoconazole NDG were characterized for various parameters like homogeneity, $\mathrm{pH}$, spreadability, extrudability, practical yield, drug content, in vitro drug release, ex vivo permeation study, and biological parameter antifungal activity.

\section{Physical appearance and homogeneity}

Except F9 and F10, all other formulations were having excellent and good homogeneity and physical appearance (table 2). Formulations were white, viscous, homogeneous free from fibres with a smooth and considered acceptable to avoid the risk of irritation upon application to the skin. This implies that NDG has better patient acceptability than other topical preparations $[15,16]$.

\section{Determination of $\mathrm{pH}$}

$\mathrm{pH}$ of all the formulations was between $\mathrm{pH}$ 6.5-7.4 (table 2), which fall in the normal $\mathrm{pH}$ range of the skin [24], which ensures the compatibility of the formulation with skin.

\section{Spreadability}

Spreadability of all the formulations under study was in between $26.65 \pm 1.33$ to $33.52 \pm 0.88 \mathrm{~g}$. cm/s (table 2), which represents the good spreading efficiency of NDG that will meet ideal quantity to the skin [24].

\section{Extrudability}

Extrudability is a useful empirical test to measure the forces required to extrude out the gel from a tube [25]. In this study out of 10 formulations prepared and tested except F9 and F10, extrudability grade of all the formulations was+++or++(table 2), which represent excellent or good extrudability of NDG.

Table 2: Characterization data of different formulations

\begin{tabular}{|c|c|c|c|c|}
\hline Formulations & Homogeneity & Spreadability (g. cm/s) & Extrudability & pH \\
\hline F1 & +++ & $32.12 \pm 1.26$ & +++ & $6.75 \pm 0.46$ \\
\hline $\mathrm{F} 2$ & +++ & $31.11 \pm 1.45$ & ++ & $6.50 \pm 0.55$ \\
\hline F3 & +++ & $33.22 \pm 0.96$ & +++ & $7.02 \pm 0.12$ \\
\hline F4 & +++ & $33.12 \pm 1.32$ & +++ & $6.88 \pm 0.32$ \\
\hline F5 & ++ & $33.52 \pm 0.88$ & ++ & $6.85 \pm 0.22$ \\
\hline F6 & +++ & $30.22 \pm 1.22$ & ++ & $7.21 \pm 0.02$ \\
\hline F7 & ++ & $29.12 \pm 1.25$ & +++ & $6.65 \pm 0.26$ \\
\hline F8 & ++ & $29.21 \pm 1.66$ & +++ & $6.52 \pm 0.66$ \\
\hline F9 & + & $27.23 \pm 1.54$ & + & $7.21 \pm 0.23$ \\
\hline F10 & + & $26.65 \pm 1.33$ & + & $7.13 \pm 0.21$ \\
\hline
\end{tabular}

(+++excellent; ++good; +fair); Data expressed in mean \pm SD, $(n=3)$

\section{Practical yield (PY)}

Table 3 shows the results of percent practical yield of all the formulations. The PY of prepared NDG was found to be in the range of $42.65 \pm 0.13 \%$ to $97.23 \pm 0.51 \%$. The maximum yield was found to be $97.23 \pm 0.51 \%$ in $\mathrm{F} 4$ formulation. These results indicated that the utilized method was efficient and appropriate for the preparation of NDG [4].

\section{Drug content}

Drug content of all the formulation is shown in table 3. Drug content of prepared NDG was in the range of $76.55 \pm 0.32 \%$ to $95.56 \pm 1.13 \%$. The maximum drug content was found to be $95.56 \pm 1.13 \%$ in formulation F4. These results indicated the high content uniformity of the formulation [18], with the results being within the pharmacopeial limits. 
Table 3: Practical yield and drug content of different formulations

\begin{tabular}{lll}
\hline Formulation & Practical yield (\%) & Drug content (\%) \\
\hline F1 & $92.02 \pm 1.25$ & $76.55 \pm 0.32$ \\
F2 & $94.23 \pm 0.92$ & $78.65 \pm 0.02$ \\
F3 & $89.32 \pm 1.21$ & $80.54 \pm 0.52$ \\
F4 & $97.23 \pm 0.51$ & $95.56 \pm 1.13$ \\
F5 & $88.32 \pm 1.03$ & $82.58 \pm 0.51$ \\
F6 & $42.65 \pm 0.13$ & $90.36 \pm 0.12$ \\
F7 & $78.20 \pm 0.65$ & $88.88 \pm 0.74$ \\
F8 & $76.50 \pm 1.51$ & $77.55 \pm 1.24$ \\
F9 & $66.50 \pm 0.94$ & $83.65 \pm 0.08$ \\
F10 & $75.23 \pm 0.65$ & $91.88 \pm 0.81$ \\
\hline
\end{tabular}

Data expressed in mean $\pm \mathrm{SD},(n=3)$

\section{In vitro dissolution studies}

Cumulative \% drug release data of various formulation is shown in table 4 and 5 . The cumulative $\%$ release of the different formulation after $24 \mathrm{~h}$ of the study was in the range of $28.56 \pm 1.06 \%$ to $96.52 \pm 0.52 \%$ while it was $49.25 \pm 1.13 \%$ after $24 \mathrm{~h}$ for pure drug ketoconazole. These data revealed that there was an enhancement in dissolution rate from all formulation when compared to pure drug ketoconazole. From the cumulative \% drug release plot, the maximum \% release $96.52 \pm 0.52 \%$, was shown by formulation F4 that contain $1 \%$ carbopol 934 and $2.5 \%$ tween 80 . This implies that formulation F4 is an optimized formulation [7, 12].

Table 4: Cumulative \% drug release data of pure drug and formulation F1 to F5.

\begin{tabular}{|c|c|c|c|c|c|c|}
\hline Time (h) & Pure drug & F1 & F2 & F3 & F4 & F5 \\
\hline 0.5 & $1.12 \pm 1.09$ & $1.54 \pm 0.08$ & $1.89 \pm 0.05$ & $2.56 \pm 0.15$ & $9.44 \pm 0.22$ & $5.01 \pm 0.15$ \\
\hline 1 & $4.35 \pm 1.12$ & $5.62 \pm 0.56$ & $7.54 \pm 1.12$ & $13.22 \pm 0.14$ & $16.64 \pm 0.41$ & $9.41 \pm 0.58$ \\
\hline 2 & $12.55 \pm 1.11$ & $14.55 \pm 0.42$ & $17.88 \pm 0.21$ & $26.33 \pm 1.10$ & $32.41 \pm 0.35$ & $22.07 \pm 1.05$ \\
\hline 4 & $18.65 \pm 0.53$ & $20.54 \pm 1.02$ & $25.66 \pm 0.24$ & $34.55 \pm 0.20$ & $43.92 \pm 0.51$ & $32.70 \pm 0.95$ \\
\hline 6 & $26.32 \pm 1.05$ & $29.33 \pm 0.56$ & $34.22 \pm 0.42$ & $55.23 \pm 1.13$ & $59.39 \pm 0.42$ & $51.20 \pm 0.24$ \\
\hline 8 & $34.22 \pm 1.25$ & $38.23 \pm 0.84$ & $45.66 \pm 0.41$ & $63.22 \pm 0.24$ & $71.53 \pm 0.36$ & $58.23 \pm 0.89$ \\
\hline 12 & $40.62 \pm 0.83$ & $44.32 \pm 0.79$ & $52.11 \pm 1.32$ & $71.33 \pm 0.12$ & $83.10 \pm 0.52$ & $68.33 \pm 1.23$ \\
\hline 16 & $48.22 \pm 1.02$ & $51.46 \pm 0.65$ & $60.12 \pm 0.35$ & $80.23 \pm 0.42$ & $96.60 \pm 0.44$ & $79.33 \pm 0.52$ \\
\hline 24 & $49.25 \pm 1.13$ & $52.23 \pm 1.26$ & $60.54 \pm 0.25$ & $83.56 \pm 0.32$ & $96.52 \pm 0.52$ & $80.21 \pm 0.55$ \\
\hline
\end{tabular}

Data expressed in mean $\pm \mathrm{SD},(\mathrm{n}=3)$

Table 5: Cumulative \% drug release data of formulation F6 to F10

\begin{tabular}{|c|c|c|c|c|c|}
\hline Time (h) & F6 & F7 & F8 & F9 & F10 \\
\hline 0.5 & $3.45 \pm 0.58$ & $2.89 \pm 0.21$ & $1.98 \pm 0.54$ & $1.20 \pm 1.01$ & $0.82 \pm 0.62$ \\
\hline 1 & $7.25 \pm 0.83$ & $6.55 \pm 0.54$ & $6.33 \pm 0.65$ & $5.65 \pm 0.89$ & $4.56 \pm 0.58$ \\
\hline 2 & $15.44 \pm 1.21$ & $10.26 \pm 1.21$ & $8.33 \pm 1.22$ & $8.10 \pm 0.65$ & $7.55 \pm 0.42$ \\
\hline 4 & $24.65 \pm 1.03$ & $18.33 \pm 1.11$ & $14.23 \pm 1.32$ & $12.22 \pm 0.52$ & $10.52 \pm 1.22$ \\
\hline 6 & $36.55 \pm 1.52$ & $29.36 \pm 1.50$ & $25.33 \pm 0.25$ & $20.65 \pm 1.06$ & $17.25 \pm 1.52$ \\
\hline 8 & $48.65 \pm 0.89$ & $35.33 \pm 0.54$ & $31.22 \pm 0.98$ & $28.66 \pm 0.84$ & $25.23 \pm 1.65$ \\
\hline 12 & $59.22 \pm 0.97$ & $44.25 \pm 0.98$ & $40.22 \pm 0.65$ & $36.55 \pm 0.54$ & $31.25 \pm 0.95$ \\
\hline 16 & $68.26 \pm 1.25$ & $56.22 \pm 0.65$ & $45.33 \pm 1.51$ & $38.25 \pm 1.02$ & $31.25 \pm 0.78$ \\
\hline 24 & $69.22 \pm 1.22$ & $58.65 \pm 1.05$ & $42.51 \pm 0.85$ & $36.52 \pm 1.21$ & $28.56 \pm 1.06$ \\
\hline
\end{tabular}

Data expressed in mean $\pm \mathrm{SD},(\mathrm{n}=3)$

\section{Ex vivo permeation study}

Table 6 shows the data of cumulative percent drug permeate of formulation F4 and marketed formulation (P). The cumulative \% drug permeate of F4 and P after $24 \mathrm{~h}$ of the study was found to be $89.12 \pm 0.63 \%$ and $68.86 \pm 1.65 \%$. Permeability coefficient of F4 and P were found to be $0.0015 \mathrm{~cm} / \mathrm{min}$ and $0.0012 \mathrm{~cm} / \mathrm{min}$ respectively.
The flux of F4 and P were found to be $2.10 \mu \mathrm{g} / \mathrm{cm}^{2} / \mathrm{min}$ and 1.69 $\mu \mathrm{g} / \mathrm{cm}^{2} / \mathrm{min}$ respectively. From the result it is clear that formulation F4 which was showing maximum cumulative \% drug release among all other formulations also showed good permeation of drug across the chicken membrane in comparison to marketed formulation (phytoral). It indicates that formulating NDG leads to enhancement in permeability of drug [26].

Table 6: Cumulative \% drug permeates data of formulation F4 and marketed formulation phytoral (P).

\begin{tabular}{lll}
\hline Time (h) & F4 (\%) & P (\%) \\
\hline 1 & $14.56 \pm 0.83$ & $7.25 \pm 1.48$ \\
2 & $29.35 \pm 1.24$ & $15.44 \pm 1.62$ \\
4 & $39.25 \pm 1.21$ & $24.65 \pm 1.24$ \\
6 & $56.25 \pm 0.43$ & $36.55 \pm 1.08$ \\
8 & $68.56 \pm 0.81$ & $48.65 \pm 0.86$ \\
12 & $80.01 \pm 1.05$ & $59.22 \pm 1.21$ \\
16 & $87.25 \pm 1.25$ & $68.26 \pm 1.07$ \\
24 & $89.12 \pm 0.63$ & $68.86 \pm 1.65$ \\
\hline
\end{tabular}

Data expressed in mean $\pm \mathrm{SD},(\mathrm{n}=3)$ 


\section{Antifungal activity}

Zone of inhibition of ketoconazole loaded NDG (S) and normal marketed ketoconazole gel (M) after $24 \mathrm{~h}$ of incubation were found to be $28.5 \pm 0.42 \mathrm{~mm}$ and $22.56 \pm 2.51 \mathrm{~mm}$ respectively. These results indicate that antifungal activity shown by prepared ketoconazole loaded NDG is more than normally marketed ketoconazole. This is due to enhanced permeation and solubility on the reduction of particle size to nano measurement $[9,20]$.

\section{CONCLUSION}

The results of these studies showed that, formulating NDG of ketoconazole lead to enhancement in solubility and dissolution behaviour of poorly soluble antifungal drug ketoconazole. Carbopol 934 used as a gelling agent that produced a gel with, an excellent physical appearance, spreadability and extrudability which proved carbopol 934 to be a promising gelling agent to prepare NDG. The formation of SMT for preparing nanodispersion was found to be satisfactory as it produced a good product with high practical yield as well as high drug content. Out of 10 formulations prepared, formulation F4 exhibit best drug release, as well as dissolution rate when compared to pure drug. Formulation F4 also showed good skin permeability and higher antifungal activity than normal marketed ketoconazole gel. Practical yield, as well as Drug content of formulation F4, was also maximum among all other formulations. Henceforth, we concluded that formulation F4 is an optimized and promising formulation for effective treatment of topical fungal infections with enhanced solubility and penetration through skin

\section{ACKNOWLEDGEMENT}

Authors are thankful to Prof. Pramod Kumar Sharma (Dean) and Prof. Nayyar Parvez (HOD), Department of Pharmacy, School of Medical and Allied Sciences, and Galgotias University for providing laboratory facilities and chemicals to conduct research work successfully.

\section{AUTHORS CONTRIBUTIONS}

Contribution of all authors are equal

\section{CONFLICT OF INTERESTS}

Authors do not have any conflict of interest to disclose

\section{REFERENCES}

1. Vicente M, Basilio A, Cabello A, Pelaez F. Microbial natural products as a source of antifungals. Clin Microbiol Infect 2003;9:15-32.

2. Sahoo AK, Mahajan R. Management of tinea corporis, tinea cruris, and tinea pedis: a comprehensive review. Indian Dermatol Online J 2016;7:77.

3. Patel RP, Patel H, Baria AH. Formulation and evaluation of liposomes of ketoconazole. Int J Drug Delivery Technol 2009;1:16-23.

4. Najmuddin M, Khan T, Mohsin A, Shelar S, Patel V. Enhancement of dissolution rate of ketoconazole by solid dispersion technique. Int J Pharm Pharm Sci 2010;2:132-6.

5. Chauhan SP, Kanojiya AD, Patel PA, Seth AK. Ketoconazole loaded solid self-emulsifying drug delivery system: formulation and in vitro characterization. Int J Pharm Sci Rev Res 2013;4:311-30.
6. Skiba M, Marchais H, Duclos R, Arnaud P. Stability assessment of ketoconazole in aqueous formulations. Int J Pharm 2000;198:1-6.

7. Guru PM, Nayar C. Emulgel: an advanced review. J Pharm Sci Res 2013;5:254-8.

8. Priya M, Sellakumar V, Natarajan R. Formulation and in vitro evaluation of ciprofloxacin loaded topical emulgel. Int J Pharm Chem Sci 2012;1:237-42.

9. Shirsand S, Para M, Nagendrakumar D, Kanani K, Keerthy D. Formulation and evaluation of ketoconazole niosomal gel drug delivery system. Int J Pharm Invest 2012;2:201.

10. Shatalebi M, Mostafavi S, Moghaddas A. Niosome as a drug carrier for topical delivery of $\mathrm{N}$-acetyl glucosamine. Res Pharm Sci 2010;5:107.

11. Khar RK, Vyas SP, Ahmed FJ, Jain Gk. Lachman/liebermans: the theory and practice of industrial pharmacy. In: Vyas SP, Vaidya B, Dubey D. editors. Novel drug delivery systems. $4^{\text {th }}$ ed. New Delhi: CBS Publishers and Distributor; 2015. p. 883-5.

12. Benipal G. Design, development and evaluation of proniosomal gel of an antifungal drug ketoconazole. Int J Pharm Sci Rev Res 2015;31:265-72.

13. Tadros TF. Nanodispersions. $1^{\text {st }}$ ed. Berlin (NY): Walter de Gruyter publisher; 2016.

14. Kapoor D, Vyas RB, Lad C, Patel M, Lal B, Parmar R. Formulation, development and characterization of emulgel of an NSAID'S. Pharm Chem J 2014;1:9-16.

15. Khullar R, Kumar D, Seth N, Saini S. Formulation and evaluation of mefenamic acid emulgel for topical delivery. Saudi Pharm J 2012;20:63-7.

16. Murthy GL, Kumar GV, Sravani B, Kumar PP, Kumar DA, Bhanu A, et al. Design and development of ofloxacin in-situ gel using mucoadhesive polymers. Sch Acad J Pharm 2017;6:212-20.

17. Guleri KT, Preet KL. Formulation and evaluation of topical gel of aceclofenac. J Drug Delivery Ther 2013;3:51-3.

18. Vishal Y, Prakash J, Dombe S, Anjali B, Salunkhe P. Formulation and evaluation of microsponge gel for topical delivery of the antifungal drug. Int J Appl Pharm 2017;9:30-7.

19. Sunil KY, Manoj KM, Anupamaa T, Shukla A. Emulgel: a new approach for enhanced topical drug delivery. Int J Curr Pharm Res 2017;9:15-9.

20. Kumar KV, Arun KN, Verma P, Rani C. Preparation and in vitro characterization of valsartan solid dispersions using skimmed milk powder as carrier. Int J PharmTech Res 2009;1:431-7.

21. Rajan R, Vasudevan DT. Effect of permeation enhancers on the penetration mechanism of transfersomal gel of ketoconazole. J Adv Pharm Technol Res 2012;3:112.

22. Ubaid M, Ilyas S, Mir S, Khan AK, Rashid R, Khan MZ, et al. Formulation and in vitro evaluation of carbopol 934-based modified clotrimazole gel for topical application. An Acad Bras Cienc 2016;88:2303-17.

23. Abitha MH, Mathew F. Formulation and evaluation of nanoparticles as sustained release topical formulation containing the non-steroidal anti-inflammatory drug. World J Clin Pharmacol Micrbiol Toxicol 2015;1:35-42.

24. Verma A. Formulation and evaluation of clobetasol propionate gel. Asian J Pharm Clin Res 2013;6:15-9.

25. Kumar KK, Sasikanth K, Sabareesh M, Dorababu N. Formulation and evaluation of diacerein cream. Asian J Pharm Clin Res 2011;4:93-8.

26. Abrar B, Anis S, Tanu B, Singh S. Formulation and in vitro evaluation of NSAID's gel. Int J Curr Pharm Res 2012;4:56-8. 